\title{
Case Report: Neuropathic pain in a patient with congenital
}

\section{insensitivity to pain [version 1; peer review: 2 approved with}

\section{reservations]}

\author{
Daniel W. Wheeler ${ }^{1}$, Michael C.H. Lee1, E. Katherine Harrison ${ }^{2}$, David K. Menon ${ }^{1}$, \\ C. Geoffrey Woods 3
}

${ }^{1}$ Division of Anaesthesia, University of Cambridge, Cambridge, CB2 0QQ, UK

${ }^{2}$ School of Clinical Medicine, University of Cambridge, Cambridge, CB2 OSP, UK

${ }^{3}$ Department of Medical Genetics, University of Cambridge, Cambridge, CB2 OQQ, UK

V1 First published: 26 Jun 2014, 3:135

https://doi.org/10.12688/f1000research.2642.1

Latest published: 19 Jun 2015, 3:135

https://doi.org/10.12688/f1000research.2642.2

\section{Abstract}

We report a unique case of a woman with Channelopathy-associated Insensitivity to Pain (CIP) Syndrome, who developed features of neuropathic pain after sustaining pelvic fractures and an epidural hematoma that impinged on the right fifth lumbar (L5) nerve root. Her pelvic injuries were sustained during painless labor, which culminated in a Cesarean section. She had been diagnosed with CIP as child, which was later confirmed when she was found to have a null mutation of the SCN9a gene that encodes the voltage-gated sodium channel Nav1.7. She now complains of troubling continuous buzzing in both legs and a vice-like squeezing in the pelvis on walking. Quantitative sensory testing showed that sensory thresholds to mechanical stimulation of the dorsum of both feet had increased more than 10-fold on both sides compared with tests performed before her pregnancy. These findings fulfill the diagnostic criteria for neuropathic pain. Notably, she only experiences the negative symptoms (such as numbness and tingling) and she has not reported sharp, burning or electric shock sensations, although the value of verbal descriptors is somewhat limited in a person who has never felt pain before. However, her case strongly suggests that at least some of the symptoms of neuropathic pain can persist despite the absence of the Nav1.7 channel. Pain is a subjective experience and this case sheds light on the transmission of neuropathic pain in humans that cannot be learned from knockout mice.

Open Peer Review
Approval Status
version 1
26 Jun 2014
(revision)
19 Jun 2015
The.....................................................................
2. Juank van E. Ratherlands. St. Elisabeth Hospital, Tilburg,
Oxford, UK
Any reports and responses or comments on the
article can be found at the end of the article.




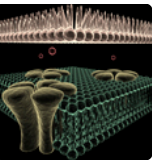

This article is included in the Ion channels in

somatosensory transmission collection.

Corresponding author: Daniel W. Wheeler (dan.wheeler@gmail.com)

Competing interests: No competing interests were disclosed.

Grant information: The author(s) declared that no grants were involved in supporting this work.

Copyright: @ 2014 Wheeler DW et al. This is an open access article distributed under the terms of the Creative Commons Attribution License, which permits unrestricted use, distribution, and reproduction in any medium, provided the original work is properly cited.

How to cite this article: Wheeler DW, Lee $\mathrm{MCH}$, Harrison EK et al. Case Report: Neuropathic pain in a patient with congenital insensitivity to pain [version 1; peer review: 2 approved with reservations] F1000Research 2014, 3:135

https://doi.org/10.12688/f1000research.2642.1

First published: 26 Jun 2014, 3:135 https://doi.org/10.12688/f1000research.2642.1 


\section{Case}

There has been an explosion of interest in Nav1.7 as a potential therapeutic target for novel analgesics, as mutations in SCN9A are associated with profoundly altered pain thresholds ${ }^{1}$. Perhaps the greatest level of interest has been reserved for those very rare individuals with autosomal recessive mutations that truncate the protein Nav1.7 resulting in a complete lack of expression of the ion channel. The result is Channelopathy-associated Insensitivity to Pain (CIP) Syndrome: a complete absence of pain sensation, while all other sensory modalities apart from the sense of smell remain intact. Here we describe the experiences of a Caucasian 37-yearold patient with CIP whose older sister, but neither of her parents or other family members, is also affected. Other than a variety of injuries to the cornea and tongue, burns and relatively minor fractures sustained during childhood and now ascribed to CIP, there was no other medical history of note. Nonetheless, after childbirth she developed a symptom that she now readily describes as pain, and which has neuropathic features. We believe that this case report provides insights into the mechanisms of neuropathic pain, dissecting "positive" from "negative" symptomatology, and shows that it is possible to experience neuropathic pain in the absence of prior experience of acute pain.

Our patient had been recognized as having CIP aged 7, diagnosed at the same time as her older sister. This diagnosis was confirmed
18 years later by finding bi-allelic heterozygous null mutations of SCN9A in exon 29 (c.4975T>A p.K1659X) and exon 22 (c.36993709delATGGATAGCAT p.I1235LfsX2). The SCN9A gene on chromosome 2q24.3 encodes the alpha-subunit of the Nav1.7 voltage-gated sodium channel, which is expressed at high levels in small-diameter peripheral nociceptive neurons ${ }^{2}$.

The patient sustained painless pelvic fractures, presumably during labor, which were not recognized for two months. By then, examination revealed significant weakness in both legs, worse on the right, and with absence of both ankle reflexes. We subsequently compared the results of formal quantitative sensory testing three months postinjury to those obtained four years pre-injury. Sensory thresholds to heat and cold in the foot dorsum were broadly similar on both sides (Table 1), and should be interpreted in the context of someone who has never felt pain. However, thresholds to mechanical (von Frey) stimulation of the dorsum of both feet were increased more than 10fold bilaterally. Imaging studies revealed multiple fractures of both sacral wings and of the superior and inferior pubic rami bilaterally. Furthermore, there was an extensive hematoma extending into the left iliopsoas, right obturator externus and spinal canal, causing occlusion of the thecal sac at the level of the fifth lumbar (L5) and first sacral (S1) intervertebral space (Figure 1). The fractures were attributed to transient osteoporosis of pregnancy, and their severity to her continued walking in the face of CIP. However, shortly after

Table 1. Temperature and mechanical thresholds of the dorsum of both feet before and after childbirth.

\begin{tabular}{|c|c|c|c|c|}
\hline \multirow{2}{*}{$\begin{array}{l}\text { Body part tested } \\
\text { Mean threshold }\end{array}$} & \multicolumn{2}{|c|}{ Dorsum right foot } & \multicolumn{2}{|c|}{ Dorsum left foot } \\
\hline & Pre-delivery & Post-delivery & Pre-delivery & Post-delivery \\
\hline "Feels cool" $\left({ }^{\circ} \mathrm{C}\right)$ & 28.6 & 20.0 & 23.6 & 25.7 \\
\hline "Feels warm" $\left({ }^{\circ} \mathrm{C}\right)$ & 42.8 & 48.7 & 47.6 & 46.4 \\
\hline "Painfully cold" $\left({ }^{\circ} \mathrm{C}\right)$ & 14.5 & 20.6 & 9.7 & 17.9 \\
\hline "Painfully hot" $\left({ }^{\circ} \mathrm{C}\right)$ & 48.0 & 46.6 & $>50.0$ & $>52.0$ \\
\hline $\begin{array}{l}\text { Mechanical detection } \\
\text { threshold (Von Frey } \\
\text { filament, g) }\end{array}$ & 0.04 & 0.65 & 0.02 & 0.99 \\
\hline
\end{tabular}
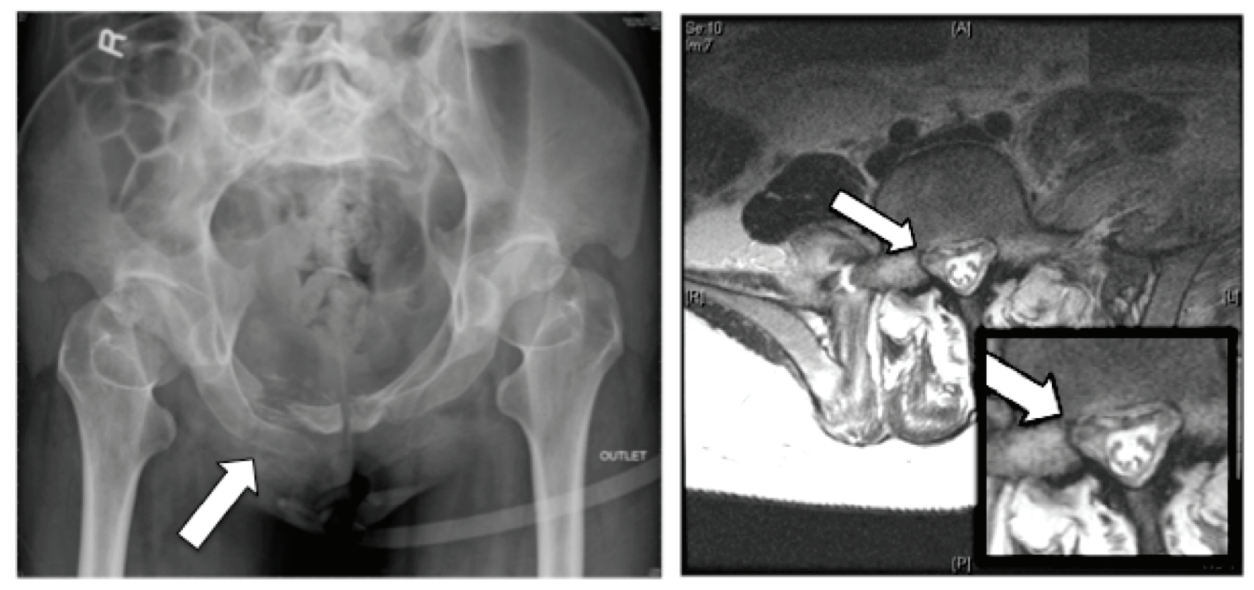

Figure 1. An anteroposterior X-ray outlet view of the patient's pelvis. The X-ray shows multiple fractures of the superior and inferior pubic rami (left) and an axial magnetic resonance image (right) plus magnification showing a hematoma impinging upon the right L5 nerve root at the exit foramen (arrow). 
the fractures were diagnosed, bone densitometry studies and all serum bone profile results were found to be normal.

Two months later, four months after delivery, she reported troubling continuous buzzing in both legs and a vice-like squeezing in the pelvis when she walked: symptoms that are consistent with neuropathic pain ${ }^{3}$. These two symptoms did not respond to the anti-neuropathic drug gabapentin, and persist two years after the delivery. Further treatment has focused on physiotherapy and conservative measures such as pacing and activity management.

Neuropathic pain arises as a direct consequence of a lesion or disease affecting the somatosensory system, and is characterized according to four criteria: pain distribution; the link between distribution and history; confirmatory tests of neurologic status demonstrating sensory signs confined to the territory of the lesioned nerve, and further confirmatory diagnostic tests to identify the lesion or disease entity underlying the neuropathic pain ${ }^{3}$. The history, examination and investigations that we have described fulfill these criteria. We therefore believe that this patient has definite neuropathic pain, although it is manifested only by 'negative' symptoms, such as numbness and tingling, with an absence of the 'positive' symptoms such as stabbing or burning, but is nonetheless becoming increasingly debilitating.

The Nav1.7 channel plays a crucial role in pain transmission. However this case shows that neuropathic pain can be initiated and maintained in its absence in humans, as well as in knockout mice ${ }^{4}$, although we cannot rule out that Nav1.7 may mediate sharp, burning or electric shock sensations. Our data provide a further rational basis for seeking specific molecular substrates for neuropathic pain, some of which could act as mechanistic targets for new therapies for patients with symptoms of neuropathic pain.

\section{Patient consent}

Written consent for the publication of this case report was obtained from the patient.

\section{Author contributions}

All authors conceived the paper. MCL undertook the post-injury quantitative sensory testing and CGW the $S C N 9 a$ genotyping. DWW wrote the first draft, which was reviewed, revised and approved by all authors.

\section{Competing interests}

No competing interests were disclosed.

\section{Grant information}

The author(s) declared that no grants were involved in funding this work.

\section{Acknowledgments}

We are indebted to the late Dr David Bowsher, who kindly shared his pre-injury quantitative sensory testing data. We are grateful to our patient, who gave written consent for the publication of this report.
1. Fischer TZ, Waxman SG: Familial pain syndromes from mutations of the NaV1.7 sodium channel. Ann N Y Acad Sci. 2010; 1184: 196-207. PubMed Abstract | Publisher Full Text

2. Cox JJ, Reimann F, Nicholas AK, et al: An SCN9A channelopathy causes congenital inability to experience pain. Nature. 2006; 444(7121): 894-8. PubMed Abstract | Publisher Full Text
Treede RD, Jensen TS, Campbell JN, et al.: Neuropathic pain: redefinition and a grading system for clinical and research purposes. Neurology. 2008; 70(18): 1630-5. PubMed Abstract | Publisher Full Text

4. Nassar MA, Levato A, Stirling LC, et al:: Neuropathic pain develops normally in mice lacking both $\mathrm{Na(v)1.7} \mathrm{and} \mathrm{Na(v)1.8.} \mathrm{Mol} \mathrm{Pain.} \mathrm{2005;} \mathrm{1:} 24$ PubMed Abstract | Publisher Full Text | Free Full Text 


\title{
Open Peer Review
}

\section{Current Peer Review Status: ? ?}

\section{Version 1}

Reviewer Report 17 September 2014

https://doi.org/10.5256/f1000research.2861.r6088

(C) 2014 Ramirez J. This is an open access peer review report distributed under the terms of the Creative Commons Attribution License, which permits unrestricted use, distribution, and reproduction in any medium, provided the original work is properly cited.

\begin{abstract}
Juan D. Ramirez
Nuffield Department of Clinical Neurosciences, University of Oxford, Oxford, UK

This is an exciting report by Wheeler et al., assessing the meaning of pain after a traumatic labour in a subject who has never experienced anything similar. This case is paramount for highlighting the importance of a detailed study of patients with inherited channelopathies.
\end{abstract}

Neuropathic pain has been established by IASP as pain arising as a consequence of damage to the somatosensory system. In this case the patient describes positive sensory phenomena in the form of buzzing and squeezing which is troubling and is accompanied by numbness which is often regarded as negative phenomena (positive and negative sensory abnormalities often co-exist in neuropathic pain states) so I would recommend changing the terms 'sensory loss' for both 'sensory gain and loss'.

One issue is whether what the subject describes is more akin to paraesthesia rather than pain as understood by healthy subjects in whom NaV 1.7 is functional. The IASP definition of pain is actually fairly broad including the term 'unpleasant sensory experience'. In the current case this sensory disturbance is an anatomically plausible distribution with evidence of a lesion to the somatosensory system.

The evidence comes from MRI that shows nerve root compression as a consequence of a haematoma. It would be helpful to have more sequences in order to demonstrate bilateral involvement and neurophysiology to define the extent of the nerve damage (sensory and motor).

The thermal and mechanical sensory testing is thorough and I would only recommend the authors to add the baseline temperature at which they started the assessment e.g. " $32^{\circ} \mathrm{C}$ " added as part of the figure legend.

Finally, I would vouch for the use of the neuropathic pain symptom inventory for assessing in more detail the symptomatology of the subject (Bouhassira et al., 2004).

In general I believe this a relevant case that illustrates the need to carefully delineate new sensory 
symptoms in patients with congenital inability to experience pain and emphasises the distinct nature of neuropathic versus nociceptive pain states.

Competing Interests: No competing interests were disclosed.

I confirm that I have read this submission and believe that I have an appropriate level of expertise to confirm that it is of an acceptable scientific standard, however I have significant reservations, as outlined above.

Author Response 12 Jun 2015

Daniel W. Wheeler, University of Cambridge, Cambridge, UK

This is an exciting report by Wheeler et al., assessing the meaning of pain after a traumatic labour in a subject who has never experienced anything similar. This case is paramount for highlighting the importance of a detailed study of patients with inherited channelopathies.

Thank you for your positive comments about our manuscript.

Neuropathic pain has been established by IASP as pain arising as a consequence of damage to the somatosensory system. In this case the patient describes positive sensory phenomena in the form of buzzing and squeezing which is troubling and is accompanied by numbness which is often regarded as negative phenomena (positive and negative sensory abnormalities often co-exist in neuropathic pain states) so I would recommend changing the terms 'sensory loss' for both 'sensory gain and loss'.

We agree, and the text has been amended as suggested.

One issue is whether what the subject describes is more akin to paraesthesia rather than pain as understood by healthy subjects in whom NaV 1.7 is functional. The IASP definition of pain is actually fairly broad including the term 'unpleasant sensory experience'. In the current case this sensory disturbance is an anatomically plausible distribution with evidence of a lesion to the somatosensory system.

The evidence comes from MRI that shows nerve root compression as a consequence of a haematoma. It would be helpful to have more sequences in order to demonstrate bilateral involvement and neurophysiology to define the extent of the nerve damage (sensory and motor).

The patient was seen in the clinical setting. Routine neurological examination revealed sensory loss to touch already suggesting neuropathy. EMG and ENG were not performed, as neither would have altered the clinical management in this case.

Please see our response to Dr van Eijs for our comment on the MRI scan.

The thermal and mechanical sensory testing is thorough and I would only recommend the authors to add the baseline temperature at which they started the assessment e.g. " $32^{\circ} \mathrm{C}$ " 
added as part of the figure legend.

The table caption has been amended to indicate that the baseline temperature was $32^{\circ} \mathrm{C}$.

Finally, I would vouch for the use of the neuropathic pain symptom inventory for assessing in more detail the symptomatology of the subject (Bouhassira et al., 2004).

Please see our response to Dr van Eijs regarding the value of pain questionnaires in patients with CIP.

Competing Interests: No competing interests were disclosed.

Reviewer Report 11 September 2014

https://doi.org/10.5256/f1000research.2861.r5741

(C) 2014 van Eijs F. This is an open access peer review report distributed under the terms of the Creative Commons Attribution License, which permits unrestricted use, distribution, and reproduction in any medium, provided the original work is properly cited.

\section{Frank van Eijs}

Department of Anaesthesiology, St. Elisabeth Hospital, Tilburg, The Netherlands

The presented aspects of the reported case are indeed interesting, however...

One cannot talk about pain if no pain is reported. Buzzing and a vice like squeezing of the pelvis is not the same as pain. The vice like squeezing of the pelvis may also have been due to the observed fractured pelvis. It is unclear if there indeed is subjective pain. If there is a report of pain there should also be an assessment of the visual analogue or numerical pain rating scale. Unfortunately this is not mentioned. Another clinical aspect is the missing of a DN4 score (douleur neuropathique 4 questionnaire). As I can see the score may not be more than 3 in which case the presence of neuropathic pain is unlikely.

The MRI scan of the L5-S1 interspace is not clear. It lacks a saggital view. The cross-sectional view should be more clearly and preferentially showing more than 1 slice.

\section{Suggestions:}

1. Add the VAS or NRS of the pain intensity (probably 0 ?) Specify if pain scores are for the feet, legs or pelvis. If pain scores are not 0 then indeed there may possibly be neuropathic pain. In that case add the DN 4 score.

2. If there is no pain, symptoms should be mentioned as neuropathic or neuropathy instead of neuropathic pain. In that case also the title needs to be changed (e.g. neuropathy in a 
patient with congenital insensitivity to pain).

3. Add the saggital view of the lumbar MRI. Show more than 1 cross-sectional view of the MRI. Specify if views are T1, T2 or contrast dye enhanced.

Competing Interests: No competing interests were disclosed.

I confirm that I have read this submission and believe that I have an appropriate level of expertise to confirm that it is of an acceptable scientific standard, however I have significant reservations, as outlined above.

Author Response 12 Jun 2015

Daniel W. Wheeler, University of Cambridge, Cambridge, UK

The presented aspects of the reported case are indeed interesting; however, one cannot talk about pain if no pain is reported. Buzzing and a vice like squeezing of the pelvis is not the same as pain. The vice like squeezing of the pelvis may also have been due to the observed fractured pelvis. It is unclear if there indeed is subjective pain. If there is a report of pain there should also be an assessment of the visual analogue or numerical pain rating scale. Unfortunately this is not mentioned. Another clinical aspect is the missing of a DN4 score (douleur neuropathique 4 questionnaire). As I can see the score may not be more than 3 in which case the presence of neuropathic pain is unlikely.

The MRI scan of the L5-S1 interspace is not clear. It lacks a sagittal view. The crosssectional view should be more clearly and preferentially showing more than 1 slice.

Suggestions:

1. Add the VAS or NRS of the pain intensity (probably 0?) Specify if pain scores are for the feet, legs or pelvis. If pain scores are not 0 then indeed there may possibly be neuropathic pain. In that case add the DN 4 score.

2. If there is no pain, symptoms should be mentioned as neuropathic or neuropathy instead of neuropathic pain. In that case also the title needs to be changed (e.g. neuropathy in a patient with congenital insensitivity to pain)

\section{Response}

The International Association for the Study of Pain (IASP) defines pain as an unpleasant sensory and emotional experience associated with actual or potential tissue damage, or described in terms of such damage. The IASP also acknowledges that application of the word 'pain' is learnt in early life (http://www.iasppain.org/Taxonomy?navItemNumber=576\#Pain). It is unclear what patients have been diagnosed with congenital insensitivity to pain (CIP) understand by the word 'pain'. However, there is psychometric and neuroimaging evidence they understand what the word 'pain' means, as they are clearly able to empathise with behavioural and verbal expressions of pain in normal individuals (Danziger et al., 2009). 
Our patient reports that her right hip and pelvis still "hurt" a great deal, using descriptors such as "tight" and "aching", and that she "suffers" if she walks too far or doesn't wear an orthotic heel raise. At rest, this "pain" resolves, but she is left with "tingling", "buzzing" and "electric shocks". The patient in our report labelled her sensations as painful and we contend that description alone is adequate to fulfil the IASP definition of pain. Furthermore she also describes headaches that respond to paracetamol, "the sting of a graze", "the sharpness of an exposed gum", and "back aches", "period pains and stomach cramps" that arose after pregnancy.

Our patient has also exhibited behavior consistent with a person in pain. She sought treatment in the local Pain Clinic (with DWW) for the sensations, which suggests that these "buzzing" and "vice-like" descriptors had strong aversive-motivational qualities. We believe that the simple verbal use of the word pain and behavioral response sufficed and have acknowledged and managed her report of pain as such. The visual analog or numeric rating scale (NRS) is undoubtedly useful in normal individuals, and our patient rates her current pain intensity in the right hip and leg as between 0 and 4 on a 10-point NRS. However, the scale should not be required to validate the report of pain by this patient.

The DN4 score aims to increase the specificity of a diagnosis of neuropathic pain, with a score $>4$ providing $90 \%$ specificity for neuropathic pain. The sensitivity of the questionnaire is not well documented and the specificity of lower scores for neuropathic pain is unclear. The score in our patient was 5 , but as the scale was validated in individuals with premorbid normal nociceptive physiology, we judge that the diagnosis of neuropathic pain stands independently of the DN4 score.

We have added several additional paragraphs to the manuscript to address these points, which we hope you will find satisfactory.

Add the sagittal view of the lumbar MRI. Show more than 1 cross-sectional view of the MRI. Specify if views are T1, T2 or contrast dye enhanced.

\section{Response}

The MRI scans are T2-weighted and non-contrast enhanced. An additional crosssectional view and a sagittal view are included below (included as Figure 1c and 1d in the revised manuscript). The arrows indicate the presence of hematoma material in the psoas and adjacent to the cauda equina.

Competing Interests: No competing interests were disclosed. 
The benefits of publishing with F1000Research:

- Your article is published within days, with no editorial bias

- You can publish traditional articles, null/negative results, case reports, data notes and more

- The peer review process is transparent and collaborative

- Your article is indexed in PubMed after passing peer review

- Dedicated customer support at every stage

For pre-submission enquiries, contact research@f1000.com 